\title{
Koplik's spots
}

\author{
Stephen Hancocks OBE \\ Editor-in-Chief
}

The BDJ Upfront section includes editorials, letters, news, book reviews and interviews. Please direct your correspondence to the News Editor,

Kate Quinlan at k.quinlan@nature.com. Press releases or articles may be edited, and should include a colour photograph if possible.

$\mathrm{T}$ here are certain facts that most of us remember from our undergraduate days that are almost time-honoured in their rarity and yet cherished for their erudition. Familiarity with the very rare Gorlin's syndrome is one and knowledge of Koplik's spots is another. These latter, oral lesions are considered pathognomonic for measles, occur a few days before the skin rash appears and thankfully are not often seen anymore in the UK due to effective vaccination administered as the Measles, Mumps, Rubella (MMR) combined vaccine.

However, sadly, measles is on the rise once again, most noticeably in the USA but also in the UK and other countries around the world. According to WHO, cases have continued to climb into this year with preliminary global data showing a rise of $300 \%$ in the first three months of 2019, compared to the same period in 2018. This follows consecutive increases over the past two years. The main reason seems to be a lack of uptake of the vaccine, the blame for which has been laid by some at the feet of social media.

Controversy had surrounded the MMR vaccine as in 1998 The Lancet carried the results of a small-scale study that claimed a link between the vaccine and autism and colitis in children.

Over successive years allegations that the study data had been falsified lead to the complete retraction of the paper by The Lancet and the General Medical Council erasing the lead author from the Medical Register for being guilty of serious professional misconduct, unnecessarily invasive tests on children and multiple, undeclared conflicts of interest. While the scientific consensus is that there is no causal link between the MMR vaccine and autism this did not prevent the public's confidence in the vaccine being seriously shaken and vaccination rates fell. Having improved somewhat in the meantime to $87 \%$ of children in England receiving both necessary doses, the level remains below the $95 \%$ coverage required to confer herd immunity. The Chief Medical Officer for England Professor Dame Sally Davies recently blamed the situation on the spreading of social media fake news, adding that parents who believe the lies circulated online by anti-vaccine campaigners 'are absolutely wrong, and urged them to ignore the naysayers.

This was followed by Health Secretary Matt Hancock calling a meeting with representatives of some of the social media companies to ask them to limit and restrict 'anti-vaxx' groups spreading their messages; as the companies had done previously for self-harm images. As a result, Facebook has announced that it will no informed professional debate to ensure that we all know what is the most up-to-date medical information. While the balance between the greater good of society as a whole and human rights is ever a difficult one, in the UK we have a track record of making sensible decisions. Compulsory car seat belt wearing attracted similar complaints of infringing individual freedom of choice (to be allowed to be catapulted through your own windscreen). A ban on smoking in public was also thought initially by politicians to be too controversial but was then rapidly implemented when it became clear that the public will was behind it. So, is it time to email social media giants and start a conversation about restricting those who oppose the

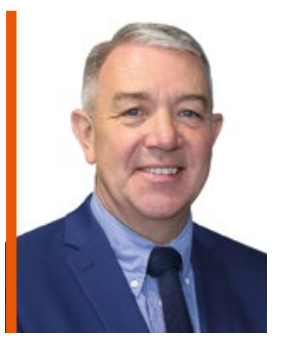

\section{'Where is the cut off point for free speech versus the public good, and who decides this?'}

longer allow advertisements that include misinformation about vaccines. It will also diminish the reach of groups and pages that spread anti-vaccine misinformation by reducing their ranking in search results and on the News Feed, removing them from autofill suggestions in the search bar, and from recommendation features such as 'Groups You Should Join'.

This seems wholly reasonable given the importance of the disease and its potential consequences, which can include death. But what of other vexatious anti-public health groups and messages? Should they have their activities curtailed on social media too? What about the anti-fluoridationists? The anti-amalgam lobby? Where is the cut off point for free speech versus the public good, and who decides this? The bedrock, as always, is the importance of good science, appropriate peer review and universally recognised, safe and effective public health measure of water fluoridation?

The 'fake news' vaccine story has prompted no less than the initiator of the term, President Trump, to urge all Americans to 'get the shot'. An important message from a quarter and a country arguably not always strong on public health interventions. For those who may be seeing more Koplik's spots in the immediate future there is one additional and slightly ironic piece of dinner-party trivia to add to the repertoire. Dr Koplik (1858-1927), who first described the eponymous markers, was a physician in New York and in recent days that same city has passed legislation to ban parents from declining MMR vaccination for their children on religious and other grounds. Biology works in mysterious ways.

DOl: 10.1038/s41415-019-0465-6 